\title{
Validation of AOGCMs Capabilities for Simulation Length of Dry Spells under the Climate Change in Southwestern Area of Iran
}

\author{
Sayed Keramat Hashemi-Ana, Mahmood Khosravi, Taghi Tavousi \\ Department of Physical Geography and Climatology, University of Sistan and Baluchestan, Zahedan, Iran \\ Email: S.climate@yahoo.com
}

Received 28 February 2015; accepted 1 June 2015; published 5 June 2015

Copyright (C) 2015 by authors and Scientific Research Publishing Inc.

This work is licensed under the Creative Commons Attribution International License (CC BY). http://creativecommons.org/licenses/by/4.0/

(c) $\underset{\mathrm{EY}}{0}$ Open Access

\section{Abstract}

Identification and extraction length of dry spells in arid and semi-arid regions is very important. Thus, the use of climate change prediction models for study the behavior of the climatic parameters in the future time is inevitable. With recognition of the spatial and temporal behavior variables such as precipitation, we can prevent from destructive effects. In this research, the performance of Atmosphere-Ocean General Circulation Models (AOGCMs) was evaluated for simulation length of dry spells in the south-western area of Iran. The results show that the length of dry spell is relatively decreased in cold seasons (autumn and winter) and increased in the warm season (spring and summer) in both $\mathrm{A} 2$ and B2 Scenarios. The length of the dry spell on monthly scale for scenario A2 is 6\% (equivalent to 2 days) and for scenario B2 is 9 percent (approximately 2.4 day) increased compared to the baseline period. For assess the uncertainty, A0GCMs were weighting. The results show that the best model for simulation of dry spells is HADCM3 and GFCM2.1, because the results have a less error. On the other hand, NCCCSM have the lowest weight for simulation dry spells in both scenarios.

\section{Keywords}

Climate Change, AOGCMs, Dry Spells, Scenarios, Southwest Iran, Simulation

\section{Introduction}

One of the major tasks of climate models is the description of precipitation characteristics. Present climate conditions already indicate important risks related to aridity over many areas of the world and they are projected to be increased for future climate conditions. Climatic Research in various parts of the world is indicating trends 
and long term variability for weather parameters like precipitation and temperature. Since the report by IPCC [1] raised the question "Has the climate become more variable or extreme". IPCC [2] reported that, during recent decades, precipitation has tended to increase in mid-latitudes, decrease in the Northern hemisphere subtropical zones, and increase generally throughout the Southern hemisphere. The intensity of extreme precipitation is projected to increase under global warming in many parts of the world, even in the regions where mean precipitation decreases [3]-[8]. Future increases in heavy precipitation are accompanied by reduction in the probability of wet days, implying a more extreme future climate with higher probabilities of droughts and heavy precipitation events.

Since Iran is located in a belt of arid and semi-arid Northern Hemisphere, there is a vital need for Reliable forecast of climate. Because water resources and agriculture are strongly influenced by the extremely drought, simulations from the majority of the atmosphere-ocean general circulation models (AOGCMs) run for the Fourth Assessment Report of the Intergovernmental Panel on Climate Change [2] produce weak annual-mean rainfall projections over region of world [9]. The description of precipitation on climatic scales and its numerical modeling is one of the most challenging issues in climate research. It exhibits a complex and irregular spatial and temporal structure. Several parameterization schemes for precipitation processes have been developed for climate models to deal with such complexities [10].

Global climate models (GCMs) show problems to describe local or regional precipitation processes, and therefore, regional climate models (RCMs) are likely to improve their climatic description [11]. A fundamental issue concerning the use of GCMs to provide regional climate change scenarios is that of horizontal resolution, despite the recent increase in computing power, Atmosphere-Ocean General Circulation Models (AOGCMs) are still run at horizontal grid intervals of $100-300 \mathrm{~km}$. [12]. Another weakness of the model errors is related to the uncertainties [13].

Uncertainties of climate change projections for precipitation are larger than for temperature, even in the sign of the change over some areas and periods [14].

When extreme events are considered, due to their intrinsic low-frequency characteristics, uncertainties are also larger [15]. So far, many studies on modeling the behavior of precipitation has been done on the basis of climate change approach around the world. But studies focused on dry spell analysis based on the output of regional climate models (RCMs) have been are rare. The mean of dry spells is likely to be related to large-scale atmospheric patterns. But it also exhibits some regional or local specific conditions, as shown by [16] over five European catchments from an ensemble of RCMs, by [17] over Switzerland, or by [18] over the Malaysia Peninsula. Other results indicate the increased maximum dry spells from regional climate models over the Mediterranean for future [15] [19]. It is associated with the climate aridity in the most seasons in this area [20].

An integrated picture of various regional models used suggest future warming, with rainfall increases in southeastern South America, and decreases in the central and eastern Amazon and Northeast Brazil regions, consistent with projections from IPCC AR4 AOGCMs [21]-[28]. In similar research, [29]-[32] made efforts on developing Long Ashton Research Station Weather Generator (LARS-WG) based on a semi-empirical distribution to simulate the wet and dry spell lengths.

The aim of this study is Validation of AOGCMs capabilities for simulation lengths of dry spells under Climate Change in the southwest area of Iran. In fact, the present study revealed which of the AOGCMs output to simulation length of dry spells have better performance?

\section{The Study Area and Dataset}

Iran is located in arid and semi-arid Southwest Asia (northern latitude between $25^{\circ} \mathrm{N}-44^{\circ} \mathrm{N}$ and the Eastern longitude from $44^{\circ} \mathrm{E}-64^{\circ} \mathrm{E}$ ) and has a variable climate. In the northwest, winters are cold with heavy snowfall and subfreezing temperatures during December and January. Spring and autumn are relatively mild, while summers are dry and hot. In the south, winters are mild and the summers are very hot, having average daily temperatures in July exceeding $38^{\circ} \mathrm{C}\left(100.4^{\circ} \mathrm{F}\right)$. On the Khuzestan Plain, summer heat is accompanied by high humidity. In general, Iran has an arid climate in which most of the relatively scant annual precipitation falls from October through April. In most of the country, annual precipitation averages $250 \mathrm{~mm}$ (9.8 in) or less. The major exceptions are the higher mountain valleys of the Zagros and the Caspian coastal plain, where precipitation averages at least $500 \mathrm{~mm}$ (19.7 in) annually. In the western part of the Caspian, rainfall exceeds $1000 \mathrm{~mm}$ (39.4 in) annually and is distributed relatively evenly throughout the year. This contrasts with some basins of the Central 
Plateau that receive $100 \mathrm{~mm}$ or less of precipitation annually.

In this research, we study Eight Synoptic stations in Southwest area of Iran located in the northern latitude between $28^{\circ} \mathrm{N}-33^{\circ} \mathrm{N}$ and the eastern longitude from $48^{\circ} \mathrm{E}-53^{\circ} \mathrm{E}$ (Figure 1 and Table 1 show local and characteristics of the study area). This area has a hot and dry climate and Rainfall is concentrated in autumn and winter, but spring and summer is very hot and dry weather. Mean monthly precipitation is than less $35 \mathrm{~mm}$. Specifications Stations and mean monthly precipitation are listed in Table 1 and Figure 2. The data used for analysis

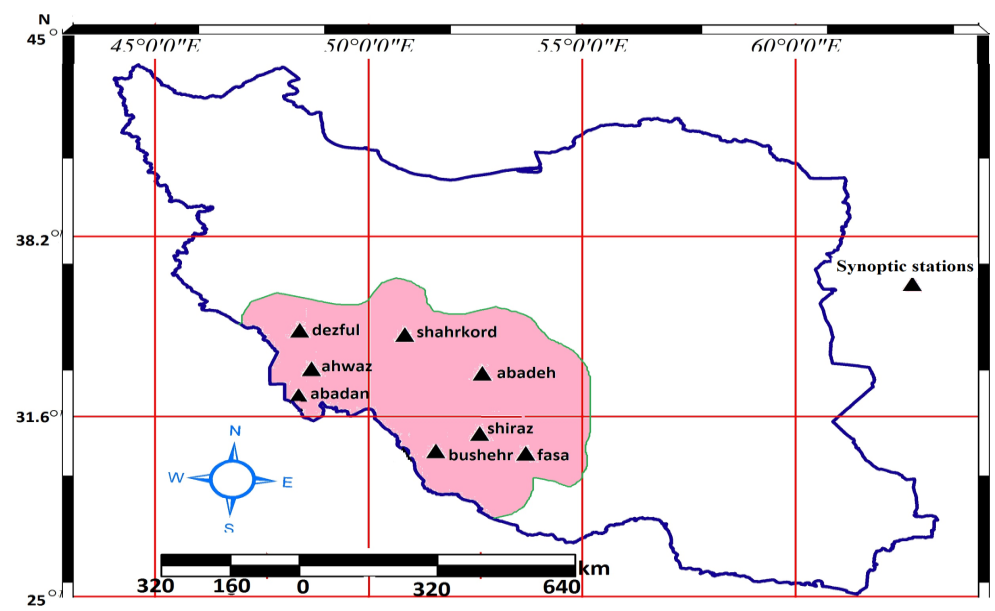

Figure 1. The location of stations in southwestern area of Iran used in this study.

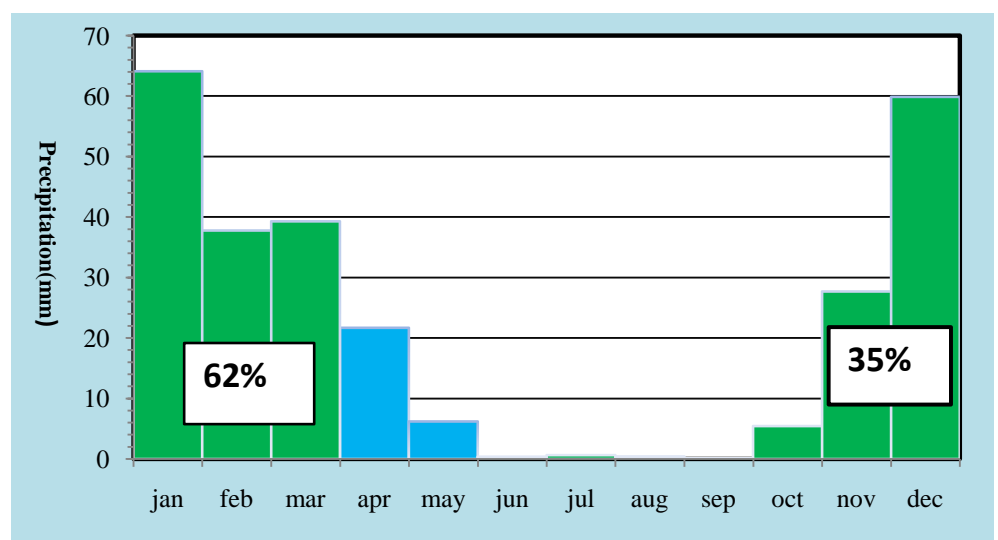

Figure 2. Mean monthly precipitation (1980-2010).

Table 1. List and a brief description of meteorological stations used in this study.

\begin{tabular}{cccccc}
\hline Station name & Latitude $\left({ }^{\circ} \mathrm{N}\right)$ & Longitude $\left({ }^{\circ} \mathrm{E}\right)$ & Elevation $(\mathrm{m})$ & Time period & Station Code \\
\hline Ahwaz & 20.31 & 40.48 & 5.22 & $1980-2010$ & 40811 \\
Abadan & 30.22 & 15.48 & 6.6 & $1980-2010$ & 40831 \\
Dezful & 33.24 & 23.48 & 143 & $1980-2010$ & 40795 \\
Shahre kord & 32.17 & 51.50 & 9.2048 & $1980-2010$ & 40798 \\
Shiraz & 32.29 & 36.48 & 1484 & $1980-2010$ & 40848 \\
Abadeh & 31.11 & 40.52 & 2030 & $1980-2010$ & 40818 \\
Fasa & 28.58 & 41.53 & 3.1288 & $1980-2010$ & 40859 \\
Bushehr & 28.59 & 49.50 & 9 & $1980-2010$ & 40858 \\
\hline
\end{tabular}

Note: The coordinate system used here is WGS1984. 
consisting two databases: the first database is daily precipitations collected from the eight synoptic station of Iran Meteorological Organization. The record length of observed daily precipitation for each station is 30 years (1980-2010). Second database is monthly precipitation data output of four models, and for future period (2014-2045) under the A2 and B2 emissions scenarios. Table 2 shows a summary of information the four models.

\section{Methodology}

Methods for this study consisted of: climate change scenarios for the future (under the A2 and B2 scenarios), downscaling AOGCMs output, analysis of the uncertainty of the models used by weighting them, the study of performance capabilities of four models, and the analysis and interpretation of research results. The following mentioned methods will be described in more details.

\subsection{Generating Climate Change Scenarios for Future Periods}

Currently, the most creditable tool for generating climate change scenarios is, three-dimensional models coupled atmosphere-ocean general circulation Models (AOGCMs).Because AOGCMs computational cells are large, for eliminating the climatic noise usually use the mean of 30 years of data Instead of using of data directly for calculations and simulation of climate change. In this research for the generation of climate change scenarios in future is used the output of four models, in baseline (1980-2010) and future period (2014-2045), under the A2 and B2 emissions scenarios (Table 2 show summary of selected 4 AOGCMs). For calculating Climate change scenarios for all models, the first must calculating "ratio precipitation" for the long-term average each month in Baseline and future period using the "Equation (1)". This equation is recommended by [26] for Calculating regional climatic time series for temperature and precipitation.

$$
\Delta P i=\left(\frac{\bar{P} G C M, \text { fut }, i}{\bar{P} G C M, \text { base }, i}\right)
$$

where $\Delta P i$ indicate Climate change scenarios the average precipitation for the 30-year period for each month of the year $(1 \leq i \leq 12), \bar{P} G C M$, fut, $i$ is 30 years average annual precipitation simulation by AOGCMs for future period (2014-2045), for each month, $\bar{P} G C M$, base, $i$ is 30 year average annual precipitation simulation by AOGCMs for data observation (1980-2010).

\subsection{Downscaling Method}

Because of the computational grid cells AOGCMs is large and the low spatial resolution, Their use in regional scale will lead to error. And simulation of surface variables such as temperature and precipitation will be accompanied by turbulence. And more importantly, there are many differences between simulated and observated data. In order to eliminate the disturbances in the models and the amplification the current climate change, instead of use direct use of output data from AOGCMs in the calculations, used the average periodic of the variables. In this research, for downscaling precipitation data, used change factor method (CFM). For computing climate change scenarios in period future in change factor method, must climate change scenarios obtained in Equation (1) multiplied in observations data value (1980-2010) is shown in Equation (2). The equation recommended by [33] for a framework assessing uncertainties in climate change impacts for the river Thames, UK.

Table 2. A summary of selected 4 AOGCMs from IPCC AR4 incorporated into the LARS-WG5.5 in this study.

\begin{tabular}{ccccc}
\hline Name of Models & Emission scenarios & Resolution(atmospheric) & Institute publication & Reference \\
\hline HADCM3 & A2, B1, A1B & $2.5^{\circ} \times 3.75^{\circ}$ & UK Met. Office & (IPCC, AR4, 2007) \\
IPCM $_{4}$ & A2, B1, A1B & $2.5^{\circ} \times 3.75^{\circ}$ & IPSL-CM4-laplace & (IPCC, AR4, 2007) \\
GFCM2.1 & A2, B1, A1B & $2^{\circ} \times 2.5^{\circ}$ & NOAA/GFDL(USA) & (IPCC, AR4, 2007) \\
NCCCSM & A2, B1, A1B & $2.8^{\circ} \times 2.8^{\circ}$ & NCAR-USA & (IPCC, AR4, 2007) \\
\hline
\end{tabular}




$$
P=P i_{o b s, b a s e \times \Delta P i}
$$

In this "Equation" $P i_{\text {obs,base }}$ is time series observations precipitation in the base line (1980-2010), $\Delta P i$, indicate climate change scenarios the average precipitation for the 30-year period for each month of the year $(1 \leq i \leq 12)$ (calculated in "Equation (1)", and $P$ is series data generated for the future period (2014-2045)).

\subsection{Analysis of Uncertainty}

In studies of climate change, there are various sources of uncertainty that affected the final results. One of the sources of uncertainty associated with the model errors. In this study we investigated the effect of uncertainty AOGCMs in precipitation Southwest area of Iran. In this study we used a Bayesian approach for reviewing and considering the uncertainty. The steps of this approach include: the production of prior probability distribution of statistical parameters, determine likelihood function probability (LFP) of the observed data and determine the posterior probability distribution (PPD). Posterior probability distribution is determined based on the input parameter distributions (prior distribution) and the probability function. to considering the Bayesian approach is needed to calculate the probability distribution function (PDF) of precipitation scenarios and then each of the models based on Mean and Standard deviation observation precipitation (MDOP) are simulated and were weighted "Equation (4)". This Equation is given by [34] for estimating uncertainty in climate change scenarios. Steps of the Bayesian approach is shown in the Figure 3 and "Equation (3)" that is given by [35]. (parts of "Equation (3)" is describe in Figure 3.

$$
\begin{array}{r}
P\left(H \mid Y, I_{0}\right)=P\left(H \mid I_{0}\right) * P(Y \mid H) \\
W i=\frac{\frac{1}{\Delta P i}}{\sum_{i=1}^{N} \frac{1}{\Delta P i}}
\end{array}
$$

$\triangle P i$ where indicate Standard deviation precipitation simulated by each of the models in the base period the month (i), $N$ is the number of AOGCMs, Wi represents weight assigned to each of the models.

\section{Results and Discussion}

\subsection{Validation of AOGCMs for Simulation in Length of Dry Spells}

Capabilities of AOGCMs for simulation length of dry spells were evaluated in (Table 3). For simulating preci-

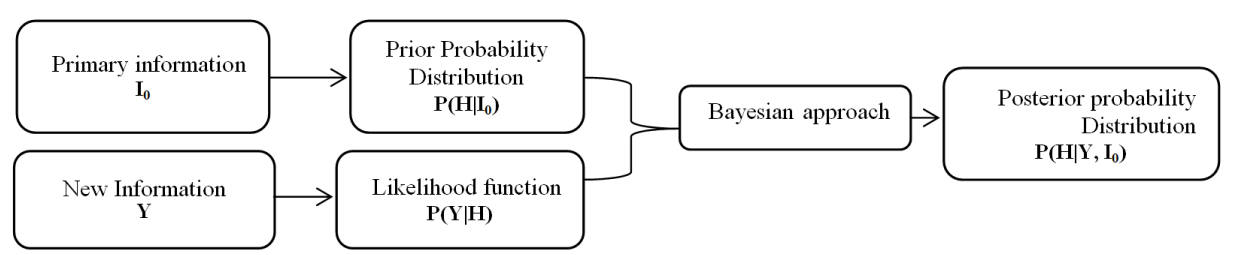

\begin{tabular}{|c|c|c|c|c|}
\hline Name of Models & Scenario & R (\%) & RMSE (mm) & MPE (\%) \\
\hline \multirow[t]{2}{*}{ HADCM3 } & $\mathrm{A} 2$ & 89.3 & 11.8 & 4.8 \\
\hline & B2 & 86.3 & 12.3 & 6 \\
\hline \multirow[t]{2}{*}{ IPCM4 } & A2 & 70.3 & 19.1 & 7.3 \\
\hline & B2 & 69.2 & 19.9 & 6.4 \\
\hline \multirow[t]{2}{*}{ GFCM2.1 } & $\mathrm{A} 2$ & 85.4 & 14.8 & 4.9 \\
\hline & B2 & 87.3 & 13.1 & 5.3 \\
\hline \multirow[t]{2}{*}{ NCCCSM } & A2 & 78.1 & 21.3 & 11.2 \\
\hline & $\mathrm{B} 2$ & 79.5 . & 25.8 & 9.8 \\
\hline
\end{tabular}

Figure 3. Schematic illustrating steps in Bayesian approach for analysis of uncertainty in this research.

Table 3. Evaluating of Performance indexes AOGCMs for simulating precipitation in this research. 
pitation and extracting length of dry spells in the Southwest area of Iran the first step, the database precipitation

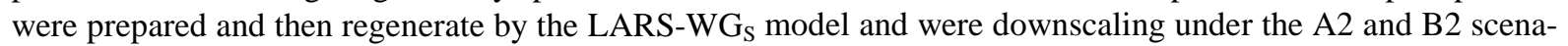
rios. For evaluating the ability of models to simulate precipitation used of 3 statistical indexes: a) the correlation coefficient (R), b) the Root Mean Square Error (RMSE) and c) Mean Percent Error (MPE). The results showed that HADCM3 and GFCM2.1 models in all of the index have less error percentage for the simulation data and more than $80 \%$ correlated with the observation data. The most percentage error of the mean is related to the NCCCSM under A2 scenario. A total of four models have a good performance to simulate precipitation (Figure 3 indicate Evaluating of Performance indexes AOGCMs).

\subsection{Calculation and Generate Climate Change Scenarios for the Future Period}

At first prepared the time series of monthly precipitation of four model AOGCMs (Table 2) are prepared and then downscaled under A2 and B2 scenarios for the Southwest area of Iran. In the second step, the long-term average of monthly precipitation for the base period (1980-2010) and simulated period (2014-2045) was calculated using equations 1 and 2 and climate change scenarios were generated. Finally, the length of dry spells monthly, were extracted under A2 and B2 scenarios for each model in the study area (Figure 4 and Figure 5). The results showed that dry spells length simulated by HADCM3 and GFCM2.1 Compared with the observated data, decreases in both scenarios, especially in cold seasons. On The other hand, dry spells length with the increasing trend is predicted by all four models in warm seasons (summer and spring).

Dry spells length in all seasons and in both scenario with the increasing trend is predicted by IPCM4 and NCCCSM models. as expected the dry spells length in the study area in the (2014-2045) period for scenario A2 on monthly basis $6 \%$ (equivalent to 2 days) and for scenario B2 9 percent (approximately 2/4 day) increased compared to the baseline. Generally we can conclude that the area studied in the next period (2014-2045) wit-

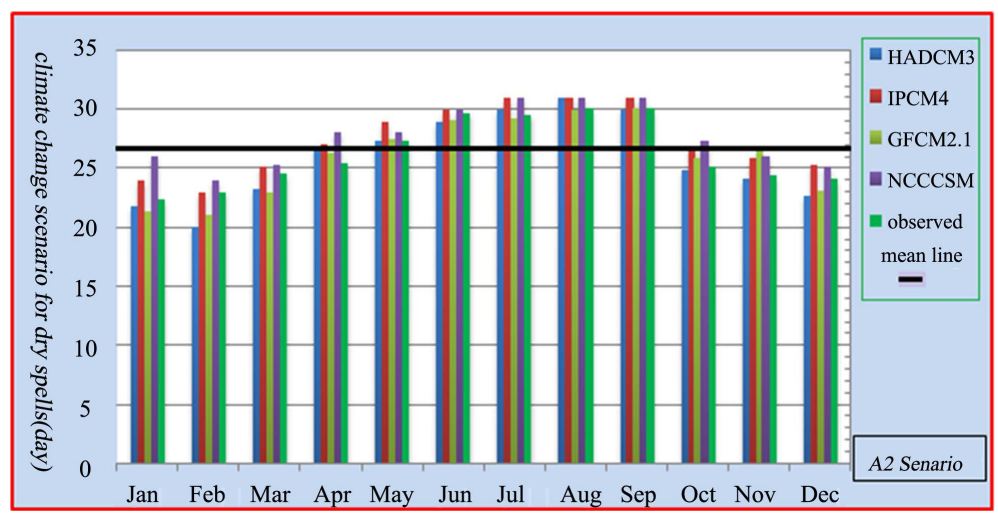

Figure 4. Climate Change scenario for dry spells simulation by AOGCMs under the A2 scenario.

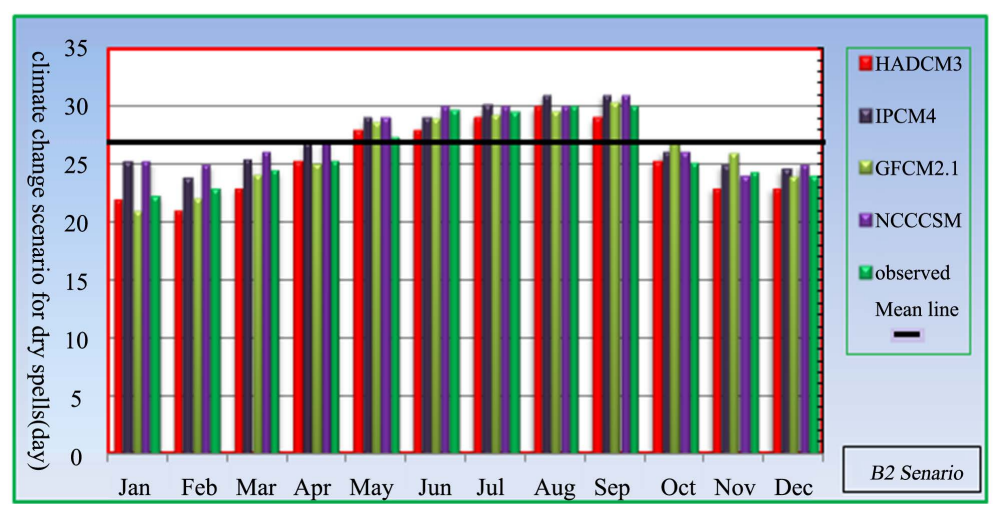

Figure 5. Climate Change scenario for dry spells simulation by AOGCMs under the B2 scenario. 
nessed a relatively shorter dry spells length in autumn and winter and in the summer and spring will be longer (Figure 4 show Climate Change for A2 scenario and Figure 5 show Climate Change for B2 scenario).

\subsection{Uncertainty Analysis of with the Approach Weighting to Models}

For reviewing an4ded considering the uncertainty of the models, after calculating and producing scenario for dry spells, each of the scenarios based on the mean and standard deviation of the observed precipitation (MDOP) were weighted and simulated by Bayesian approach. Finally, the probability distribution function (PDF) was calculated (Equations (3) and (4)). The results of these calculations show that the model HADCM3 compared to the other models have the maximum weight to estimate and simulation length of dry spells in both the A2 and B2 scenarios. On The other hands NCCCSM have the lowest weight in estimation of dry spells length in both scenarios (Figure 6 and Figure 7). In fact, if the weight of a model 4 is greater, Performance and accuracy is more acceptable. HADCM3 and GFCM2.1 have more performance in determining dry spells length, especially during the cold winter months. But NCCCS and IPCM 4 models have a good performance in warm months (Jun, Jul, Aug and Sep).

It seems that because of the consistency behavior and, reducing the occurrence of precipitation in the warm months of the year. This causes allow somewhat is reduced the estimated standard deviation of precipitation by models at scenario generation stage (Figure 6 and Figure 7). After weighting and considering the uncertainty of the models, it was found that length of dry spells in the Study area in January, December and February is getting 5 - 6 percent shorter and 3 - 12 percent longer in the warm months(jun, jul, aug and sep), (Figure 8).

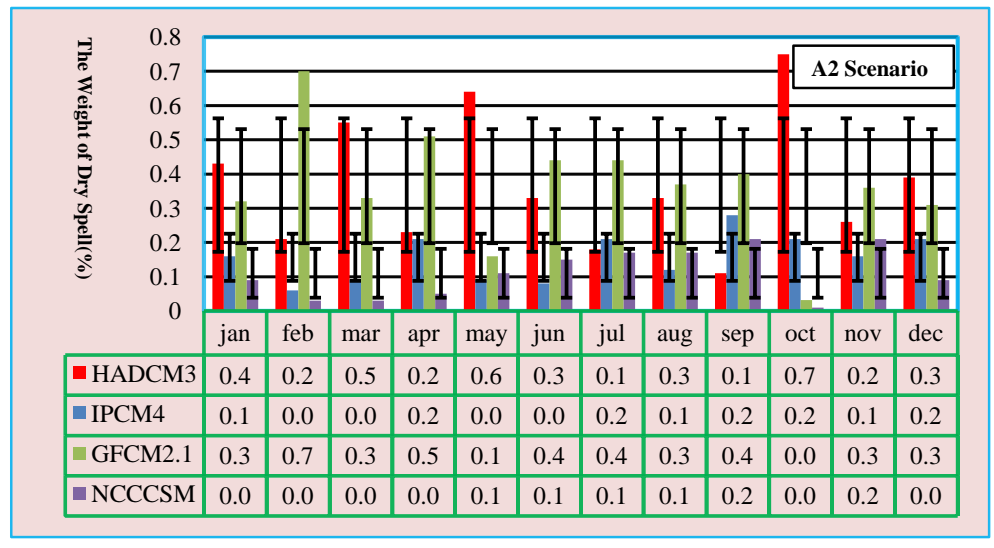

Figure 6. AOGCMs weighted values for simulated dry spells length under the A2 scenario.

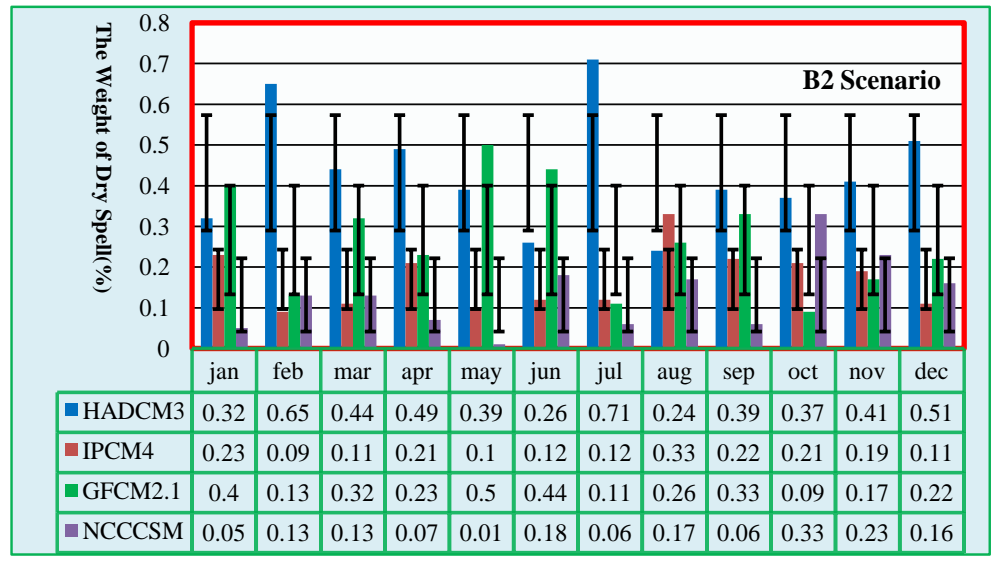

Figure 7. AOGCMs weighted values for simulated dry spells length under the B2 scenario. 


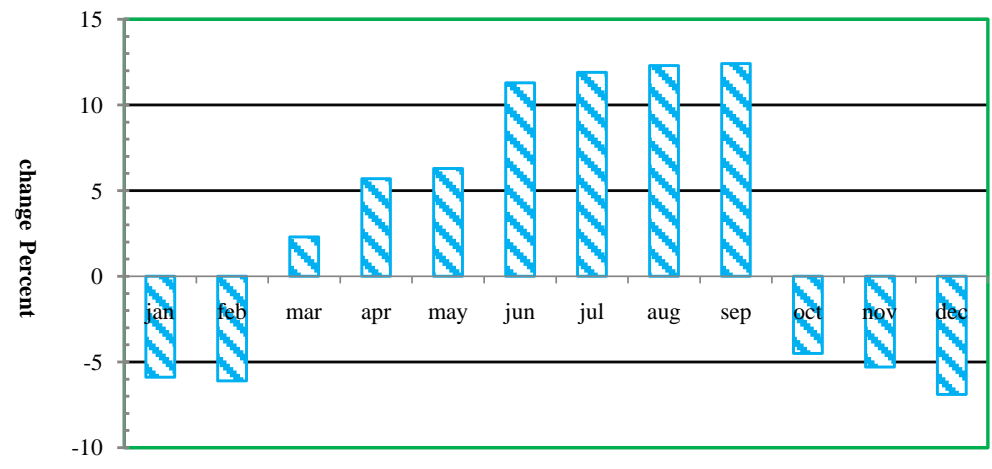

Figure 8. The scenario of Monthly variations for dry spells length, with considering the uncertainty AOGCMs.

\section{Conclusions}

In this research, the performance of AOGCMs for the simulation length of dry spells under the A2 and B2 scenario in the southwestern area of Iran were investigated.

The analysis of climate change scenarios in precipitation from AOGCMs showed that dry spells length is decrease in HADCM3 and GFCM2.1 models especially in cold seasons (autumn and winter) in both A2 and B2 scenarios. The other hand, dry spells length with the increasing trend is predicted by all four models in warm seasons (summer and spring). After weighting and considering the uncertainty of the models, it was found that length of dry spells in the Study Area in January, December and February is getting 5 - 6 percent shorter and 3 12 percent longer in the warm months (JJAS) (Figure 7). The results showed that the best model to simulate the dry spells length is HADCM3 and GFCM2.1 because the simulation results have less error percentage. Overall it can be concluded that the studied area in future periods (2014-2045) witnessed a relatively that length dry spells short in autumn and winter and will be longer in summer and spring.

\section{Acknowledgements}

The authors would like to acknowledge the Iran Meteorological Organization for providing the data and technical support. Thanks to all software developers, especially to Semenov M. A. (LARS-WG) for their valuable support and prompt feedbacks through e-mail contacts.

\section{References}

[1] IPCC (1995) Climate Changes: Contribution of Working Group I to the Second Report of the Intergovernmental Panel on Climate Change. 141-193.

[2] IPCC (2007) Climate Change 2007: Synthesis Report. Contribution of Working Group to the Fourth Assessment Report of the Intergovernmental Panel on Climate Change (IPCC). Cambridge University Press, Cambridge.

[3] Kharin, V.V. and Zwiers, F.W. (2000) Changes in the Extremes in an Ensemble of Transient Climate Simulations with a Coupled Atmosphere-Ocean GCM. Journal of Climate, 13, 3760-3788. http://dx.doi.org/10.1175/1520-0442(2000)013<3760:CITEIA>2.0.CO;2

[4] Semenov, V.A. and Bengtsson, L. (2002) Secular Trends in Daily Precipitation Characteristics: Greenhouse Gas Simulation with a Coupled AOGCM. Climate Dynamics, 19, 123-140. http://dx.doi.org/10.1007/s00382-001-0218-4

[5] Voss, R., May, W. and Roeckner, E. (2002) Enhanced Resolution Modeling Study on Anthropogenic Climate Change: Changes in Extremes of the Hydrological Cycle. International Journal of Climatology, 22, 755-777. http://dx.doi.org/10.1002/joc.757

[6] Wilby, R.L. and Wigley, T.M.L. (2002) Future Changes in the Distribution of Daily Precipitation Totals across North America. Geophysical Research Letters, 29, 39-44. http://dx.doi.org/10.1029/2001GL013048

[7] Schmidli, J. and Frei, C. (2005) Trends of Heavy Precipitation and Wet and Dry Spells in Switzerland during the 20th Century. International Journal of Climatology, 25, 753-771. http://dx.doi.org/10.1002/joc.1179

[8] Wehner, M.F. (2004) Predicted Twenty-First-Century Changes in Seasonal Extreme Precipitation Events in the Parallel Climate Model. Journal of Climate, 17, 4281-4290. http://dx.doi.org/10.1175/JCLI3197.1 
[9] Karmalkar, A.V., Bradley, R.S. and Diaz, H.F. (2011) Climate Change in Central America and Mexico: Regional Climate Model Validation and Climate Change Projections. Climate Dynamics, 37, 605-629.

[10] Sanchez, E., Domínguez, M., Romera, R., de la Franca, N.L., Gaertner, M.A., Gallardo, C. and Castro, M. (2011) Regional Modeling of Dry Spells over the Iberian Peninsula for Present Climate and Climate Change Conditions. Climatic Change, 107, 625-634. http://dx.doi.org/10.1007/s10584-011-0114-9

[11] Rowell, D.P. (2006) A Demonstration of the Uncertainty in Projections of UK Climate Change Resulting from Regional Model Formulation. Climatic Change, 79, 243-257. http://dx.doi.org/10.1007/s10584-006-9100-z

[12] Chou, S.C., Marengo, J.A., Lyra, A.A., Sueiro, G., Pesquero, J.F., Alves, L.M. and Tavares, P. (2012) Downscaling of South America Present Climate Driven by 4-Member HadCM3 Runs. Climate Dynamics, 38, 635-653.

[13] Khan, M.S., Coulibaly, P. and Dibike, Y. (2006) Uncertainty Analysis of Statistical Downscaling Methods Using Canadian Global Climate Model Predictors. Hydrological Processes, 20, 3085-3104. http://dx.doi.org/10.1002/hyp.6084

[14] Christensen, J.H. and Christensen, O.B. (2007) A Summary of the Prudence Model Projections of Changes in European Climate during This Century. Climatic Change, 81, 7-30. http://dx.doi.org/10.1007/s10584-006-9210-7

[15] Beniston, M., Stephenson, D.B., Christensen, O.B., Ferro, C.A.T., Frei, C., Goyette, S., Halsnaes, K., Holt, T., Jylhä, K., Koffi, B., Palutikof, J.P., Schöll, R., Semmler, T. and Woth, K. (2007) Future Extreme Events in European Climate: An Exploration of Regional Climate Model Projections. Climatic Change, 81, 71-95. http://dx.doi.org/10.1007/s10584-006-9226-z

[16] Blenkinsop, S. and Fowler, H.J. (2007) Changes in European Drought Characteristics Projected by the Prudence Regional Climate Models. International Journal of Climatology, 27, 1595-1610. http://dx.doi.org/10.1002/joc.1538

[17] Schmidli, J. and Frei, C. (2005) Trends of Heavy Precipitation and Wet and Dry Spells in Switzerland during the 20th Century. International Journal of Climatology, 25, 753-771. http://dx.doi.org/10.1002/joc.1179

[18] Deni, S.M., Jemain, A.A. and Ibrahim, K. (2010) The Best Probability Models for Dry and Wet Spells in Peninsular Malaysia during Monsoon Seasons. International Journal of Climatology, 30, 1194-1205. http://dx.doi.org/10.1002/joc.1972

[19] Gao, X., Pal, J.S. and Giorgi, F. (2006) Projected Changes in Mean and Extreme Precipitation over the Mediterranean Region from a High Resolution Double Nested RCM Simulation. Geophysical Research Letters, 33, 3706-3709. http://dx.doi.org/10.1029/2005GL024954

[20] Gao, X. and Giorgi, F. (2008) Increased Aridity in the Mediterranean Region under Greenhouse Gas Forcing Estimated from High Resolution Simulations with a Regional Climate Model. Global and Planetary Change, 62, 195-209.

[21] Vera, C., Silvestri, G., Liebmann, B. and González, P. (2006) Climate Change Scenarios for Seasonal Precipitation in South America from IPCC-AR4 Models. Geophysical Research Letters, 33, 707-801.

[22] Boulanger, J.-P., Martinez, F. and Segura, E.C. (2006) Projection of Future Climate Change Conditions Using IPCC Simulations, Neural Networks and Bayesian Statistics. Part 1: Temperature Mean State and Seasonal Cycle in South America. Climate Dynamics, 27, 233-259. http://dx.doi.org/10.1007/s00382-006-0134-8

[23] Boulanger, J.-P., Martinez, F. and Segura, E.C. (2007) Projection of Future Climate Change Conditions Using IPCC Simulations, Neural Networks and Bayesian Statistics. Part 2: Precipitation Means State and Seasonal Cycle in South America. Climate Dynamics, 28, 255-271. http://dx.doi.org/10.1007/s00382-006-0182-0

[24] Marengo, J.A., Ambrizzi, T., Da Rocha, R.P., Alves, L.M., Cuadra, S.V., Valverde, M.C. and Ferraz, S.E. (2010) Future Change of Climate in South America in the Late Twenty-First Century: Intercomparison of Scenarios from Three Regional Climate Models. Climate Dynamics, 35,1073-1097. http://dx.doi.org/10.1007/s00382-009-0721-6

[25] Grimm, A. and Natori, A. (2006) Climate Change and Interannual Variability of Precipitation in South America. Geophysical Research Letters, 33, 19-23. http://dx.doi.org/10.1029/2006gl026821

[26] Jones, P.D, and Hulme, M. (1996) Calculating Regional Climatic Time Series for Temperature and Precipitation: Methods and Illustrations. International Journal of Climatology, 16, 361-377. http://dx.doi.org/10.1002/(SICI)1097-0088(199604)16:4<361::AID-JOC53>3.0.CO;2-F

[27] Li, W., Fu, R. and Dickinson, R.E. (2006) Rainfall and Its Seasonality over the Amazon in the 21st Century as Assessed by the Coupled Models for the IPCC AR4. Journal of Geophysical Research: Atmospheres, 111, 55-63. http://dx.doi.org/10.1029/2005JD006355

[28] Meehl, G., Covey, C., Delworth, T., Latif, M., McAvaney, B., Mitchell, J.F.B., Stouffer, R.J. and Taylor, K.E. (2007) The WCRP CMIP3 Multimodel Data Set: A New Era in Climate Change Research. Bulletin of the American Meteorological Society, 88, 1383-1394.

[29] Schoof, J.T. and Pryor, S.C. (2008) On the Proper Order of Markov Chain Model for Daily Precipitation Occurrence in the Contiguous United States. Journal of Applied Meteorology and Climatology, 47, 2477-2486. http://dx.doi.org/10.1175/2008JAMC1840.1 
[30] Semenov, M.A. and Brooks, R.J. (1999) Spatial Interpolation of the LARS-WG Stochastic Weather Generator in Great Britain. Climate Research, 11, 137-148. http://dx.doi.org/10.3354/cr011137

[31] Racsko, P., Szeidl, L. and Semenov, M. (1991) A Serial Approach to Local Stochastic Weather Models. Ecological Modelling, 57, 27-41. http://dx.doi.org/10.1016/0304-3800(91)90053-4

[32] Dastidar, A.G., Ghosh, D., Dasgupta, S. and De, U.K. (2010) Higher Order Markov Chain Models for Monsoon Rainfall over West Bengal, India. Indian Journal of Radio and Space Physics, 39, 39-44.

[33] Wilby, R.L. and Harris, I. (2006) A Framework for Assessing Uncertainties in Climate Change Impacts: Low-Flow Scenarios for the River Thames, UK. Water Resources Research, 42, 2419-2429. http://dx.doi.org/10.1029/2005WR004065

[34] Katz, R.W. (2002) Techniques for Estimating Uncertainty in Climate Change Scenarios and Impact Studies. Climate Research, 20, 167-185. http://dx.doi.org/10.3354/cr020167

[35] Zellner, A. (1971) An Introduction to Bayesian Inference in Econometrics. Wiley, New York. 